\title{
Management of Early Loss of first Permanent Molar in
}

\section{Adolescent}

Roaa Zamzam ${ }^{1}$ and Chaza Kouchaji ${ }^{2 *}$

${ }^{1}$ Ongoing Master Degree

${ }^{2}$ Head of Syrian pedodontic associasion. Prof. at pedodontics department, Faculty of dental medicine, Damascus University, Syria.

Correspondence Author: Chaza Kouchaji, Head of Syrian pedodontic associasion. Prof. at pedodontics department, Faculty of dental medicine, Damascus University, Syria.

Received date: March 08, 2021; Accepted date: April 27, 2021; Published date: May 08, 2021

Citation: Zamzam R. and Kouchaji C. (2021) Management of Early Loss of first Permanent Molar in Adolescent. Clinical Medical Reviews and Reports 3(5); DOI:10.31579/2690-8794/077

Copyright: (02021 Chaza Kouchaji, This is an open access article distributed under the Creative Commons Attribution License, which permits unrestricted use, distribution, and reproduction in any medium, provided the original work is properly cited.

\begin{abstract}
The first molar is the largest tooth in the oral cavity and bears the maximum occlusal load, and they influence the vertical distance of the maxilla and mandible, the occlusal height, and aesthetic proportions. Since they have the maximum root surface area, they are also considered the best source of anchorage for moving the teeth (Mostafa Rezaie el al 2018). The timing of first molar eruption makes these teeth vulnerable to dental caries. The loss of a permanent first molar in adolescent patient creates a need for early space maintenance and restorative of function.

This paper describes a conservative, functional and cost-effective bridge as an interim restoration after the loss of permanent first molar in an early adolescent dentition (Rajashekhara el al 2012)

Keywords: first molar, permanent, interim restoration
\end{abstract}

\section{Introduction}

The first permanent molar (FPM) emerges early, so is more prone to dental caries and possible premature extraction before 15 years of age and is certainly the most important unit of mastication and is essential in the development of functionally desirable occlusion (Afnan M. Saber el al 2018). The early loss of a permanent first molar can lead to changes in the dental arches, these changes include diminished local function, drifting of teeth, and continued eruption of opposing teeth.

Early orthodontic and-or prosthetic treatment of the edentulous space is necessary to prevent or reduce the negative consequences of early extraction. But in this case the patient refuses orthodontic treatment.

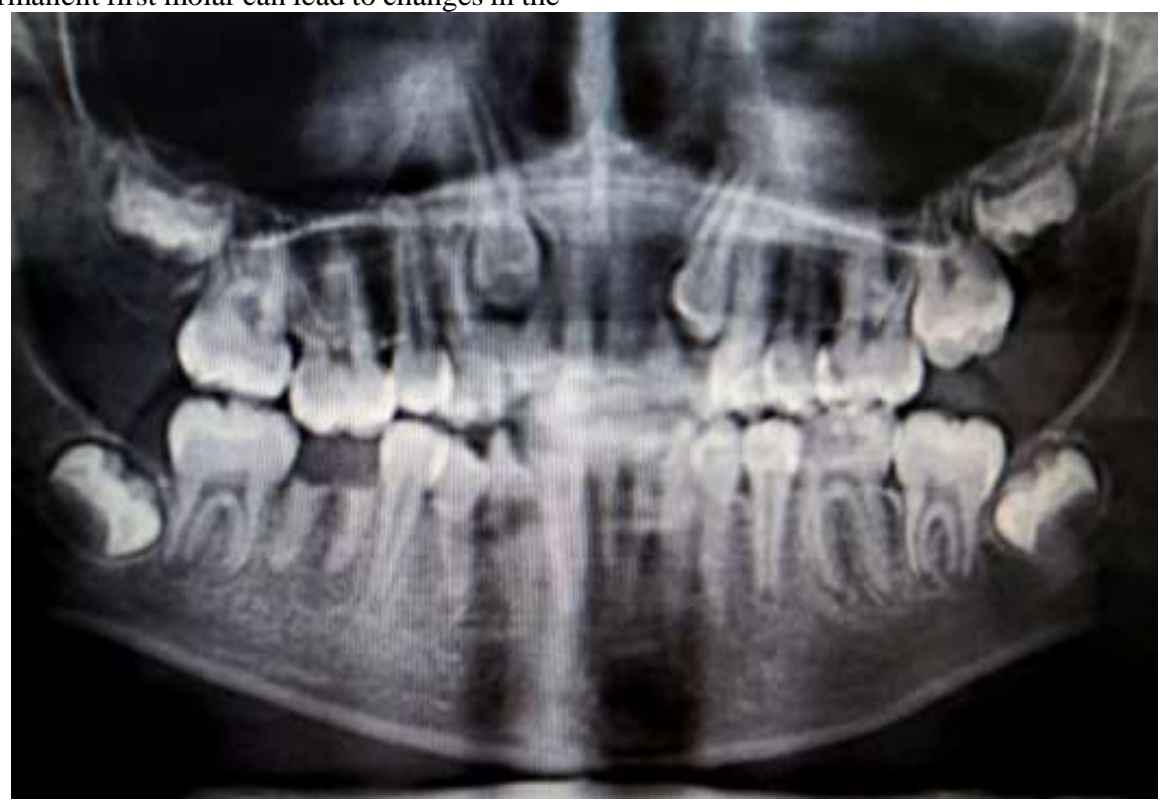




\section{Case Report}

A 13-years-old female with no relevant systemic history reported with carious lower permanent first molar. On examination 36 and 46 were deeply carious. 36 was planned for direct pulp treatment. Whereas 46 was extracted. $47 \& 45$ restorative treatment (class 1 , composite resin).
The second molar position was acceptable. Design-dependent and requires the abutment teeth to have adequate structure This bridge was intended to remain in place until the patient occlusion is enough to receive a permanent prosthetic replacement or an implant.

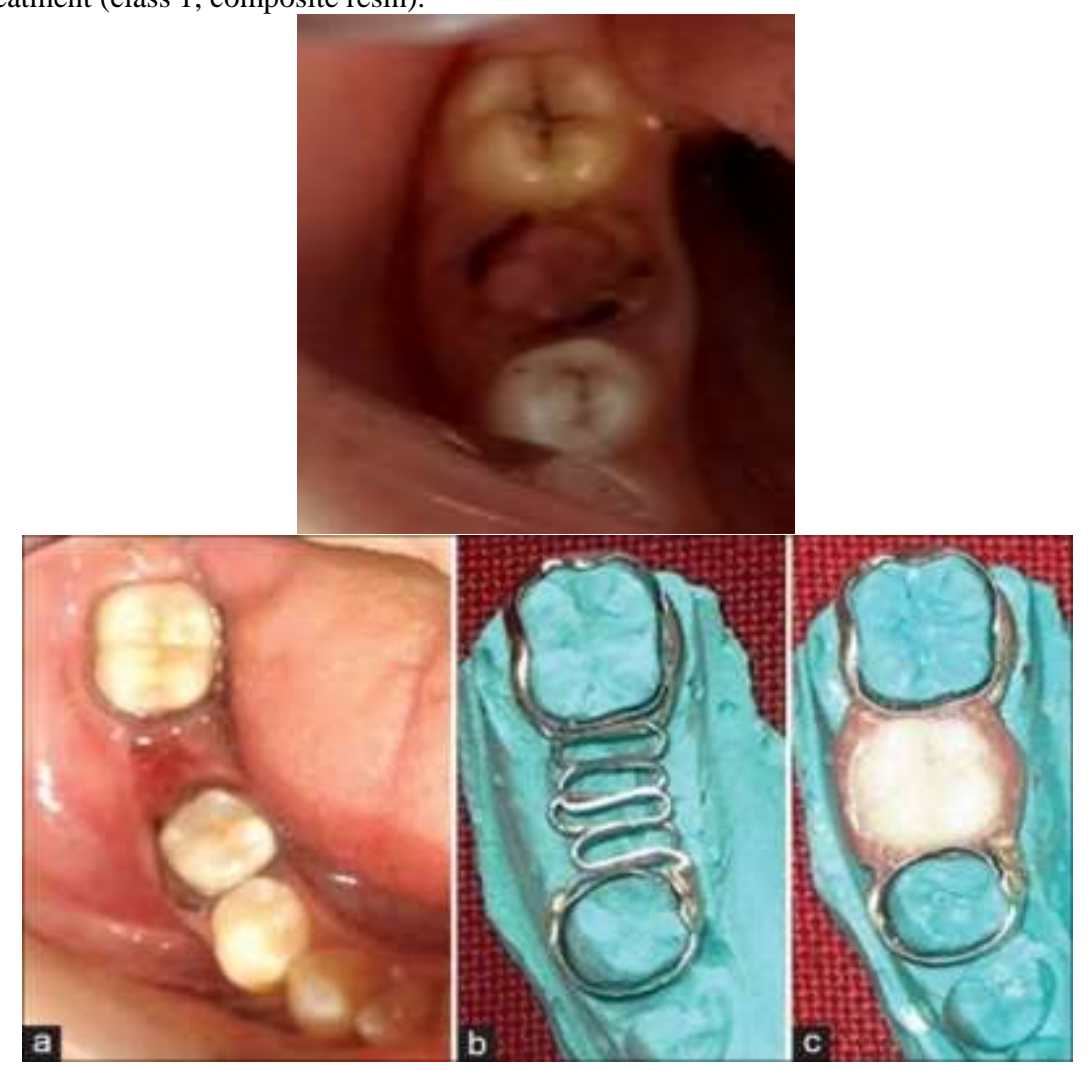

\section{Technique}

The technique devised by (Rajashekhara el al 2012). Band adaptation was done for the mesial and distal abutment teeth: second premolar Alginate impression of both the arches were made. A wire mesh was constructed by bending $26-G$ stainless steel orthodontic wires. The width of mesh was 4-mm less than the bucco-lingual width of the crowns. The mesh served to hold the three units of bridge together, the gingival extension of the wire mesh was placed $1 \mathrm{~mm}$ above the ridge to allow adequate cleansing while not allowing food entrapment or gingival irritation. The bridge was ready for a try in, in the patients for final adjustments. The occlusal and eccentric movements were adjusted. The bridge was cemented with Fuji 1 Glassionomer luting cement.

\section{Discussion}

The bridge is functional, readily acceptable, maintains the mesiodistal dimensions of the lost tooth, prevents supra eruption of opposing teeth and does not restrict normal growth and development, as is required of an ideal space maintainer. It is easy to construct, needs a short fabrication time and the materials are easily available in pediatric dental clinic

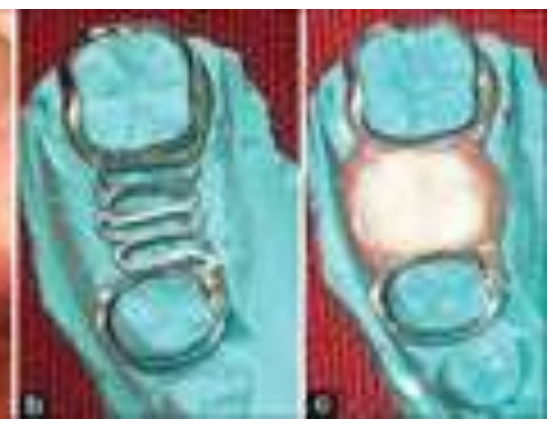

Since the laboratory technique is simple. The appliance has been shown to have an excellent patient compliance and is easy to clean and maintain.

The bridge can be easily removed and recemented for fluoride application at recall appointments, if the need arises (Rajashekhara el al 2012).

\section{Reference}


1. Rajashekhara, B. S., Keyur, J. M., Bhavna, D., \& Poonacha, K. S. (2012) Management of early loss of first permanent molar: A new technique. Journal of Indian Society of Pedodontics and Preventive Dentistry, 30(4), 349.

2. Gururaj, G. (2014) Interim fixed space maintainer: a new technique. Annals \& Essences of Dentistry. 6(1).

3. Rezaie, M., Ghapanchi, J., Haghnegahdar, A., Khojastehpour, L., Khorshidi, H., \& Heidari, H. (2018) A Radiographic Evaluation of Missing of Permanent First Molars in a Group of Iranian Children and Adults: A Retrospective Study. International journal of dentistry.

4. Saber, A. M., Altoukhi, D. H., Horaib, M. F., El-Housseiny, A. A., Alamoudi, N. M., \& Sabbagh, H. J. (2018) Consequences of early extraction of compromised first permanent molar: a systematic review. BMC oral health, 18(1), 1-15.
This work is licensed under Creative Commons Attribution 4.0 License

\section{To Submit Your Article Click Here: Submit Manuscript}

DOI: $10.31579 / 2690-8794 / 077$
Ready to submit your research? Choose Auctores and benefit from:

* fast, convenient online submission

* rigorous peer review by experienced research in your field

* rapid publication on acceptance

* authors retain copyrights

* unique DOI for all articles

* immediate, unrestricted online access

At Auctores, research is always in progress.

Learn more www.auctoresonline.org/journals/clinical-medical-reviewsand-reports 